\title{
Research Article \\ Differentially Expressed Salivary Proteins in Dental Caries Patients
}

\author{
Zaid Majeed Khan, ${ }^{1}$ Humera Waheed, ${ }^{2}$ Zohaib Khurshid $\left(D^{\circ},{ }^{3}\right.$ Muhammad Sohail Zafar ${ }^{(D},{ }^{4,5}$ \\ Syed Faraz Moin ${ }^{D},{ }^{1}$ and Mohammad Khursheed Alam (iD) ${ }^{6}$
}

${ }^{1}$ National Center for Proteomics, University of Karachi, Karachi 75270, Pakistan

${ }^{2}$ Dow College of Biotechnology, Dow University of Health Sciences, Karachi 75270, Pakistan

${ }^{3}$ Department of Prosthodontics and Dental Implantology, College of Dentistry, King Faisal University, Al Ahsa 31982, Saudi Arabia

${ }^{4}$ Department of Restorative Dentistry, College of Dentistry, Taibah University, Al Madinah, Al Munawwarah 41311, Saudi Arabia

${ }^{5}$ Department of Dental Materials, Islamic International Dental College, Riphah International University, Islamabad, Pakistan

${ }^{6}$ Preventive Dentistry Department, College of Dentistry, Jouf University, Saudi Arabia

Correspondence should be addressed to Syed Faraz Moin; faraz.moin@uok.edu.pk and Mohammad Khursheed Alam; mkalam@ju.edu.sa

Received 12 February 2021; Revised 2 September 2021; Accepted 22 September 2021; Published 14 October 2021

Academic Editor: Mauricio Budini

Copyright (c) 2021 Zaid Majeed Khan et al. This is an open access article distributed under the Creative Commons Attribution License, which permits unrestricted use, distribution, and reproduction in any medium, provided the original work is properly cited.

\begin{abstract}
Dental caries is a multifactorial disease mainly caused by cariogenic bacteria commonly found in the oral cavity. Dental caries may cause demineralization of the tooth, cavitation, hypersensitivity, pulp inflammation, and even tooth loss if left untreated. Saliva secreted in the oral cavity can serve as a tool for identification of biomarkers for early detection of diseases. In the present study, differential expression of salivary proteins from 33 dental caries patients was compared with 10 control subjects. The unstimulated saliva was analyzed by $12 \%$ SDS-PAGE and two-dimensional gel electrophoresis. Gelatin and casein zymography was performed to check for protease activity. Also, salivary IgAs from both groups were compared by sandwich ELISA technique. Dental caries patient's saliva showed decreased caseinolytic and increased gelatinolytic activity probably due to metalloproteases and cathepsins. Mean salivary levels of sIgA were also significantly higher $(p<0.018)$ in dental caries saliva samples. The $2 \mathrm{D}$ electrophoresis profile of both the groups showed regions on gel with visually detectable alterations in protein expression. The present study is among the few initial studies in the locality for identification of protein differences in saliva from dental caries patients and has demonstrated a good potential to identify alterations. However, a large population-based analysis is required to validate these findings to be translated as a tool for indicative applications.
\end{abstract}

\section{Introduction}

Dental caries (tooth decay) is a common oral condition cause by acids produced by bacteria resulting in dissolution of tooth surface. It is a multifactorial and highly prevalent disease that is related to unhealthy lifestyle of a person. There are about 3.5 billion cases related to oral conditions of which about 2.3 billion are those related to permanent teeth while 532 million cases of dental caries related to primary teeth $[1,2]$. Tooth decay is caused by a complex interaction of cariogenic bacteria residing in dental biofilm (plaque) that ferment dietary carbohydrates, produce an acidic $\mathrm{pH}$, and result in demineralization and cavitation. If the condition remains untreated, then it spreads to pulp causing pain and finally leads to tooth loss $[3,4]$. The key etiological factors include high consumption of sugary food and beverages, poor hygiene, low salivary function, and fluoride deficiency. Factors like social class, geographical location, race, age, and sex are also influential in developing caries $[5,6]$.

Saliva is secreted mainly from three major and several minor salivary glands. Whole mouth saliva (WMS) consists of water, proteins, peptides, electrolytes, minerals, and 
microorganisms which play an important role in saliva function and maintaining oral homeostasis [7, 8]. In addition, saliva aids in lubrication, speech, mastication, digestion of food, taste sensing, wound healing, and overall protection of teeth and the oral cavity [9]. The protein concentration of saliva is around $2.0 \mathrm{mg} / \mathrm{mL}$ [10]. However, under various systemic and pathological conditions, the concentration of salivary protein expression may be altered. Despite small proportion, salivary proteins may play a protective or an unprotective role in the oral cavity. For example, lactoferrin, peroxidases, and lysozyme act as cariogenic bacterial inhibitor and modulators of the mineralization and demineralization process [11]. Other salivary peptides such as histatins, defensins, statherin, and cathelicidins control oral flora and thus serve a protective role $[12,13]$. On the other hand, certain proteins have shown to have cariogenic roles by promoting colonization and proliferation of oral microbes. For instance, common salivary protein-1 can bind to Streptococcus mutans and enhances its adherence to salivary pellicle formed on hydroxyapatite surfaces suggesting its cariogenic role by promoting bacterial colonization on the surface of the tooth [14]. Besides, the role of many salivary proteins particularly in disease pathogenesis is still obscure. The main reason is that most of the functional elucidation of salivary proteins is obtained through classical proteomics and biochemical analysis. High-throughput proteomics studies and tools may comprehensively help in the characterization and functional translation of all salivary proteins [15].

It is evident that WMS reflects the physiological status of the oral cavity and the whole body. A study of drug monitoring following the model of transmembrane transport had shown that many of the saliva constituents are released by active transport, diffusion, and extracellular ultrafiltration from glands, blood, serum, and tissues of the oral cavity [16]. The significance of saliva as a diagnostic tool comes from the fact that it involves a safer, noninvasive, inexpensive collection process that requires minimal processing and trained workers. Also, multiple samples can be collected easily with minimal infection risk and cold storage conditions [17]. Most of the oral pathological conditions can be prevented or have decreased severity and increased therapy success if detected at an early stage. There is abundance of components in saliva that could be used as biomarkers for diagnosis, prognostication, treatment planning, and posttherapy monitoring for both local and systemic diseases [18]. For example, various factors such as salivary flow rate, its buffering capacity, and other constituents are associated with caries risk [19]. The main antibody in saliva is secretory immunoglobulin A (sIgA) with small fractions of other antibodies. The concentrations of these antibodies keep changing with age and are independent on gender [20]. The sIgA provides immunity by inhibition of microbial adhesion, toxins, and enzyme neutralization and by reducing hydrophobicity in synergism with lactoferrin and lysozymes [21]. Studies conducted on children suggest increased susceptibility to dental caries due to deficiency of sIgA and increased expression during caries suggesting a protective role; however, there is contradiction on correlation between dental caries and sIgAs [22-24]. In addition, matrix metalloproteinases (MMPs) and cathepsins are associated with dental caries progression and pathogenesis. MMPs are produced by odontoblasts that promote dentin formation and become entrapped in calcified matrix during collagen matrix mineralization process. Under acidic environment, the entrapped MMPs become activated and destroy matrix components $[25,26]$. Among the members of MMP family, MMP-8 and MMP-9 in dentin and saliva are mainly associated with proteolytic activity and thus promote dentin degradation [27].

Therefore, the current study was conducted to compare the differential expression of proteins in saliva of normal and dental caries patients. According to the best of authors' knowledge, the present study is the first one reporting the use of casein zymography for salivary protease analyses and also the first report of saliva proteins in caries patients of local population.

\section{Material and Method}

2.1. Patient Recruitment and Saliva Processing. The present study recruited a total of 33 dental caries and 10 control patients (caries-free at the time of sample collection, no lesions) according to the convenience (nonprobability) sampling method. The sample size was kept according to suitability to easily collect the data. The study participants (age: 20-50 years of either sex) were in good overall general health with no history of smoking or pan/gutka chewing, diabetes, or any other oral/systemic disease for at least last 3 months. The dental caries status of all the participants was analyzed according to the International Caries Detection and Assessment System (ICDAS) during the clinical examination between $9 \mathrm{AM}$ and $11 \mathrm{AM}$ by a dentist in clinical practice in the city of Karachi, Pakistan. After the clinical examination, patients were asked for a gentle mouth rinsing with water, and unstimulated saliva (a minimum of $2 \mathrm{~mL}$ ) was collected by a passive drooling method in sterile polypropylene tubes on ice. Participants abstained from eating or taking medication at least 2 hours prior to sample collection. Samples were cold centrifuged for $15 \mathrm{~min}$ at high speed $(7000 \mathrm{rpm})$ to remove any solid particles from the oral cavity. The supernatant was separated and stored at low temperature $\left(-20^{\circ} \mathrm{C}\right)$ until further analysis. This study was approved by the Institutional Ethical Committee, University of Karachi (IBC KU-94/2020), and an informed consent was obtained from each participant.

2.2. Protein Estimation. Total salivary protein concentration was estimated through the bicinchoninic acid (BCA) protein estimation kit (Thermo Scientific ${ }^{\mathrm{TM}}$ Pierce $^{\mathrm{TM}}$ ) as instructed by the manufacturer [28]. Bovine serum albumin (BSA) protein was used to develop the standard curve, and the absorbance was recorded at $562 \mathrm{~nm}$ [29].

2.3. Protein Analysis by Sodium Dodecyl Sulfate-Polyacrylamide Gel Electrophoresis (SDS-PAGE). The proteins in individual and pooled saliva samples were analyzed in reducing and nonreducing conditions on 12\% SDS-PAGE according to the procedure described by Laemmli [30]. Electrophoresis was performed for 2 hours at constant $70 \mathrm{~V}$. After completion, gels 
were fixed overnight in gel fixing solution (50\% methanol, 6\% acetic acid, and $0.025 \%$ formaldehyde). Gels were then washed $3 \mathrm{x}$ using the deionized distilled water. Protein bands were visualized by staining with Coomassie Brilliant Blue R-250 $(0.02 \% w / v)$.

2.4. Zymographic Analysis. The protease activity in dental caries patients and controls (individual and pooled saliva samples for increased resolution and sensitivity) was analyzed by casein and gelatin zymography. Saliva samples were run on to $12 \%$ polyacrylamide gels copolymerized with either $0.3 \%$ gelatin or casein as a protease substrate. Previously, casein was solubilized in $10 \mathrm{mM}$ Tris- $\mathrm{HCl}$ ( $\mathrm{pH} 8.8)$ while gelatin was simply solubilized in deionized water at $37^{\circ} \mathrm{C}$. After electrophoresis, gels were washed with wash buffer (Tris- $\mathrm{HCl}$, $2.5 \%$ Triton X-100) twice with constant shaking for $30 \mathrm{~min}$ to remove SDS. Gels were placed in an activation buffer (Tris- $\mathrm{HCl}$, calcium chloride, and Triton X-100) overnight at $37^{\circ} \mathrm{C}$. The next day, gels were visualized after staining with Coomassie Blue and destaining with deionized water.

2.5. 2-Dimesional Electrophoretic Analysis. The differential expression of proteins in both the groups was mapped by $2 \mathrm{D}$ gel electrophoresis (PROTEAN IEF system, Bio-Rad Laboratories, USA) as described previously [31]. Briefly, the pooled saliva $(80 \mu \mathrm{g})$ from dental caries and control groups was mixed in rehydration buffer and loaded on to immobilized $\mathrm{pH}$ gradient $(7 \mathrm{~cm}, \mathrm{pH} 3-10$; Bio-Rad) gel strips. Strips were layered with mineral oil and rehydrated for 14-16 hours at room temperature. The next day, isoelectric focusing (IEF) was performed as follows: $200 \mathrm{~V}(1 \mathrm{~min}), 3000 \mathrm{~V}(1.5 \mathrm{hrs})$, and $3500 \mathrm{~V}$ ( $3 \mathrm{hrs}$ ) to reach $12000 \mathrm{~V} / \mathrm{hr}$. The IPG strips were reduced in equilibration buffer $(50 \mathrm{mM}$ Tris-HCl-pH 8.8 , $6 \mathrm{M}$ urea, $2 \%$ SDS, $30 \%$ glycerol, and $10 \mathrm{mg} / \mathrm{mL}$ DTT) for 30 minutes followed by alkylation $(0.5 \mathrm{M}$ Tris- $\mathrm{HCl}$ pH 6.8, $12 \mathrm{M}$ Urea, $10 \%$ SDS, $60 \%$ glycerol, and $25 \mathrm{mg} / \mathrm{mL}$ iodoacetamide) for 30 minutes. The proteins were then separated based on their molecular weight in second dimension on $12 \%$ SDSPAGE gels and visualized by Coomassie Brilliant Blue R-250.

2.6. Gel Analysis. Differential expression patterns of proteins in SDS-PAGE, zymogram, and 2D gels from diseased (caries) and control gels were analyzed via gel analysis software (PD Quest, Version 8.0, Bio-Rad). Also, in zymography, gel band intensities in both groups were measured with Bio-6000 gel scanner (from Bioimager, Canada) and were compared.

2.7. Secretary IgA (sIgA) Analysis by ELISA. Salivary secretory IgA levels of both the groups were analyzed by sandwich ELISA by using ELISA Kit (Catalog No. E-EL-H1275 96T). Experiment was performed according to the manufacturer's instructions. Each sample was analyzed in duplicate, and the absorbance was recorded at a wavelength of $450 \mathrm{~nm}$. Secretory IgA concentration was determined from a calibration curve established from a standard antibody provided with the kit. The sIgA concentration between control and diseased (caries) groups was compared statistically by using Student's $t$-test (unpaired). The $p$ value of $<0.05$ was considered significant.

\section{Results}

3.1. SDS-PAGE Reducing and Nonreducing Condition. The salivary analysis of pooled control and dental caries groups on SDS-PAGE showed similar results under reducing and nonreducing conditions. The clear protein bands ranging from $>240 \mathrm{kDa}$ to $<6.5 \mathrm{kDa}$ were observed (Figure 1 ). However, the individual samples from both groups showed variation in low molecular weight bands that are easily observed and more in number in diseased (caries) group as compared to the control group (data not shown). It has been reported earlier that the apparent molecular weight, number, and intensity of the bands vary from individual to individual due to genetic phenotypic polymorphism [32]. Mainly, mucins and proline-rich protein (PRP) vary due to certain factors like age, oral hygiene, and oral conditions such as caries. Mucins are 200-100 kDa molecular weight proteins while PRPs such as PRP1 present in saliva is a $30 \mathrm{kDa}$ protein $[33,34]$. Our results of pooled samples also showed the same pattern of bands in control and diseased (caries) groups irrespective of the concentrations loaded on to the gel. The results reported by Schwartz et al. of resting pooled saliva where the individual saliva samples were also analyzed present the same observations on SDS-PAGE as were obtained during this study [35].

3.2. Zymography of Saliva Samples. The proteolytic activity of two groups was compared by gelatin (Figure 2(a)) and casein (Figure 2(b)) zymography performed on individual and pooled saliva samples. The individual samples showed wide diffused bands of activity throughout the respective lanes in gel even with low concentrations (data not shown). However, the pooled samples showed increased band resolution on both zymographic gels. Visual analysis showed an increase in the proteolytic activity by increasing the sample concentration. In dental caries patients, increased gelatinolytic activity and decreased caseinolytic activity were observed in comparison to controls (Figure 2). This proteolytic activity may be associated with increased proteases such as cathepsins and metalloproteases. The apparent molecular weight of different proteases was $\sim 140,80,70,50$, and $40 \mathrm{kDa}$ in the gelatin gels (Figure 2(a)) and $\sim 115,80$, and $70 \mathrm{kDa}$ (Figure 2(b)) in casein gels. In gelatin zymogram, activity bands at a molecular weight of $\sim 40$ and $50 \mathrm{kDa}$ were not observed in control saliva samples. Also, diffused bands were observed in gelatin zymogram probably due to increase protease activity and close proximity of molecular weight of the enzymes.

The band intensities of selected bands (Figures 2(a) and 2(b)) on gelatin and casein of controls and diseased were analyzed by using MAX 10000 imager software. The area of intensity was analyzed (Figures 2(c) and 2(d)). The data also supports increase in protease activity in the dental caries group compared to the controls in gelatin zymographs. In casein zymography, band at 115 and $70 \mathrm{kDa}$ is more intense in controls (band 1 and 3) as compared to dental caries group. However, band at $80 \mathrm{kDa}$ (band 2) showed slight difference in intensity (Figure 2(d)).

3.3. 2D Gel Electrophoresis. The differential proteome map of pooled saliva samples of both the groups was obtained by $2 \mathrm{D}$ 


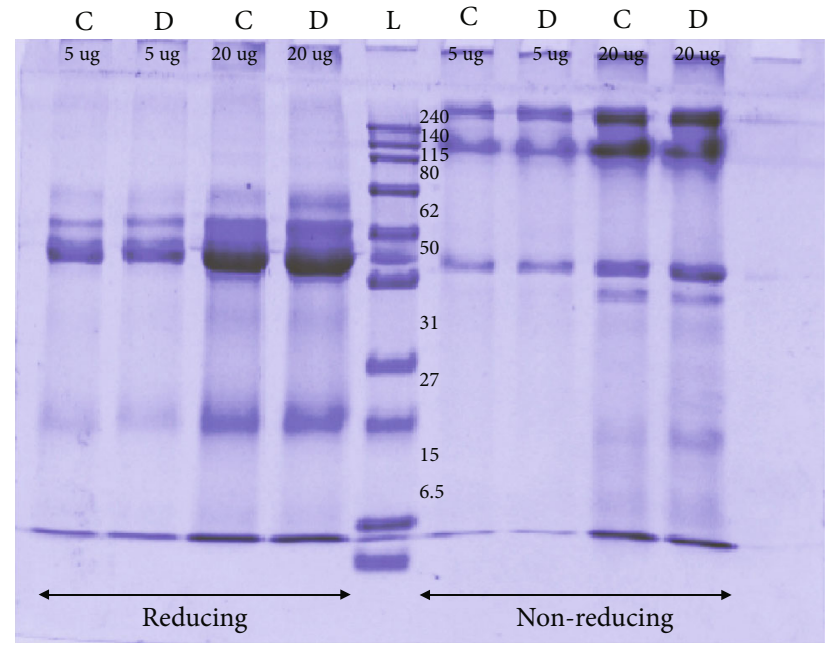

Figure 1: SDS-PAGE analysis of saliva: pooled saliva samples of control (C) and diseased (caries) (D) patients were run using $12 \%$ SDS-PAGE gels. The concentration of saliva loaded in each well starting from left to right is $5 \mu \mathrm{g}$ lanes 1 and 2, C and D, respectively, and $20 \mu \mathrm{g}$ lanes 3 and $4, \mathrm{C}$ and $\mathrm{D}$, respectively, under reducing conditions. Lane 5 is molecular weight marker. Lanes 6 and 7, $5 \mu \mathrm{g} \mathrm{C}$ and D, respectively, and lanes 8 and 9, $20 \mu \mathrm{g} \mathrm{C}$ and $\mathrm{D}$, respectively, under nonreducing conditions.

gel electrophoresis (Figure 3). For isoelectric focusing, strips of $\mathrm{pH}$ gradient (3-10) were used followed by $12 \%$ SDS-PAGE. Gels were visualized, and images were taken by using PD Quest software. Most of the protein's spots were not resolved due to spot clustering caused by higher concentration of amylase and immunoglobulins in saliva (dark patches). However, a few proteins showed differential expression among both the groups. Proteins spots in circles A, B, and C showed higher expression in the diseased (caries) group while circle $\mathrm{D}$ showed proteins that were only expressed in controls.

3.4. Detection of IgAs by ELISA. Sandwich ELISA was used to compare salivary levels of sIgAs among both the groups in nanograms per milliliter. The mean salivary IgA levels were found to be high in caries patient while low levels were detected in the control group (Figure 4). Student's $t$-test (unpaired) showed the significant differences with a $p$ value equal to 0.018 which is less than 0.05 (standard cut-off value to determine significant differences among groups). The mean \pm SD sIgA levels were found to be 41.89 in the dental caries and $33.53 \mathrm{ng} / \mathrm{mL}$ in the control group. Table 1 also represents the lowest and highest values of $\operatorname{sgA}$ obtained in both group samples.

\section{Discussion}

Saliva is an emerging source for disease biomarker identification and analysis due to its stress-free, simple, noninvasive collection methods [31,36]. Any pathological or abnormal condition results in alteration of salivary composition. This makes saliva as one of the most important sources where biomarkers for the existence and advancement of dental problems may be explored. Bacteria are the main causative agents associated with caries formation and therefore activate the host immune system to release antimicrobial agents in saliva including immunoglobulins like IgA and IgG, lactoferrin, lysozyme, hypothiocyanite, peroxidase/myeloperoxidase, and agglutinins [37].

The present study analyzed the differential expression of salivary proteins from dental caries patients and healthy individuals. For this purpose, the saliva samples of participants were analyzed using various analytical techniques including SDS-PAGE, zymography, and sandwich ELISA. The present study revealed decreased caseinolytic and increased gelatinolytic activity in the diseased (caries) group likely due to metalloproteases and cathepsin proteins. Bacterial and host proteases (from dentin and saliva) are altogether responsible for dentin extracellular matrix degradation in carious decay process. Saliva contains gelatinases (MMP-2, MMP-9), collagenases (MMP-1, MMP-8, and MMP-13), enamelysin (MMP-20), and cysteine cathepsins of various types [27, 38, 39]. Bacterial acids promote demineralization, degrades SIBLINGs (Small Integrin-binding Ligand N-linked Glycoproteins), and activates host pro-MMPs to digest dentin matrix. MMP-2, MMP-9, and MMP-8 have been detected from carious lesion by gelatin zymography and Western blot analysis [40]. In addition, increased expression of MMP-13 has been observed in caries dentin by immunohistochemical analysis [41]. On the other hand, cathepsins (B and L) under mild acidic conditions initiate matrix degradation, activate pro-MMPs, and degrade native type I collagen [42]. In our study, increase in protease activity was observed in dental caries patients which may be associated with increased expression of MMPs and cathepsins. Contrary to gelatin zymography, an increased caseinolytic activity in the control group was observed compared to the diseased (caries) group while overall protease activity is less as observed on gelatin gels. This may be attributed to the difference in source of two substrates, i.e., gelatin (derived from collagen) and casein (obtained from milk). Casein is a nonspecific substrate and is less sensitive for proteases particularly collagenases $[43,44]$. The use of casein zymography for salivary protease analyses is so far the first report as no other study has been found utilizing casein zymography for saliva protease analysis.

Secretory IgAs are predominant immunoglobulin found in saliva and act as the first line of defense against infectious nature of cariogenic microorganisms. sIgAs inhibit not only microbial attachment but also their toxins by immune exclusion mechanisms. It also protects the epithelial surfaces by controlling symbiotic association between host and commensals [45]. Secretary IgAs are also found to interrupt certain virulence factors and cause decrease in inflammation by controlling cytokine and interleukin response [46]. Analysis of dental caries and control saliva samples for sIgA detection by ELISA showed significant increased expression in the caries group ( $p$ value $<0.018$ ). On the basis of molecular mass, increased expression of immunoglobulins was observed in the two-dimensional (2D) gels (Figure 3, circle A) as more intense spots were noted at the resolution point of sIgAs according to Ghafouri et al. [47]. Similar to our findings, de Farias and Bezerra and Thaweboon et al. also stated that dental caries is associated with increased levels of salivary sIgA 


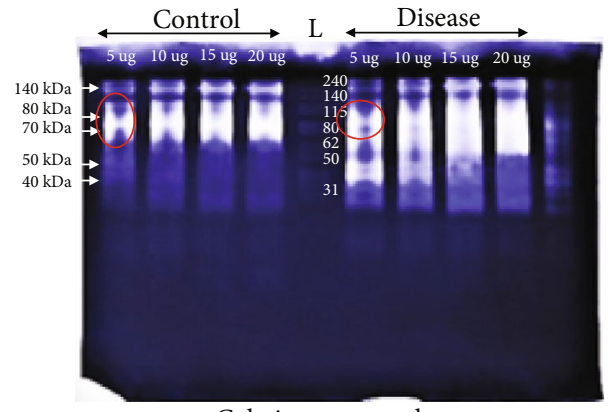

Gelatin zymography

(a)

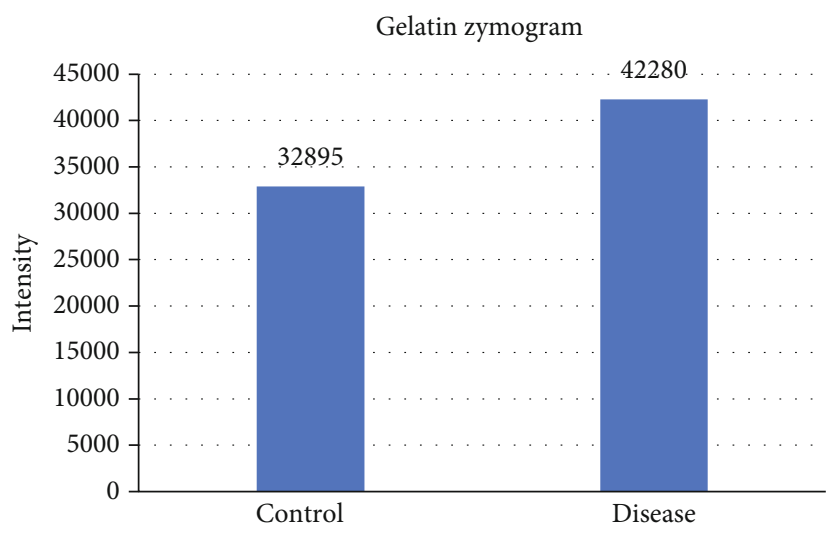

(c)

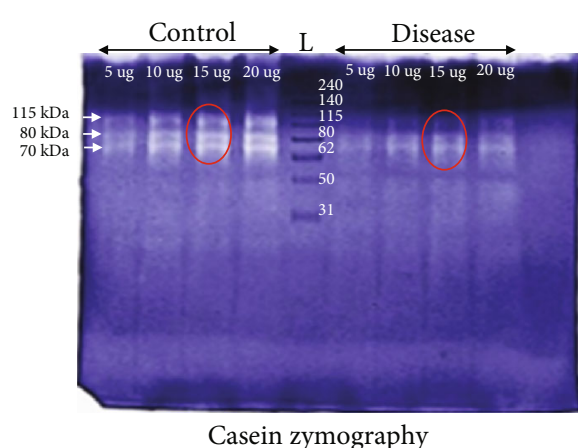

(b)

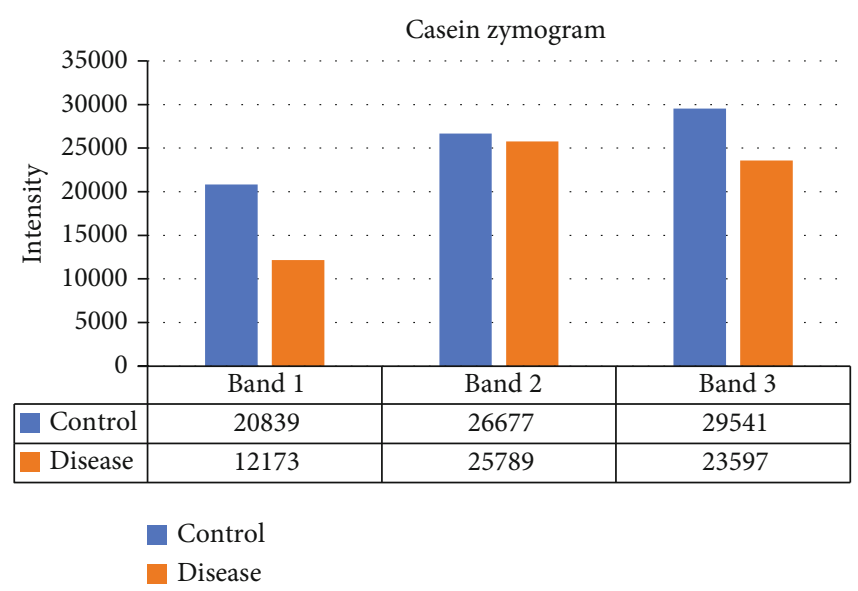

(d)

FIGURE 2: Zymographic analysis of saliva: (a) gelatin zymogram and (b) casein zymogram of pooled saliva sample of controls and dental caries patients. Lanes left to right showed increasing concentration of controls and diseased (caries) samples. On the left side of each gels, apparent molecular weights of proteases were mentioned. (c) Bar graph for protease activity area comparison on the basis of band intensity of gelatin zymogram (80 kDa band) and (d) casein zymogram (115, 80, $70 \mathrm{kDa}$, respectively). Red circles represent activity regions used for intensity. (L) Molecular weight marker.

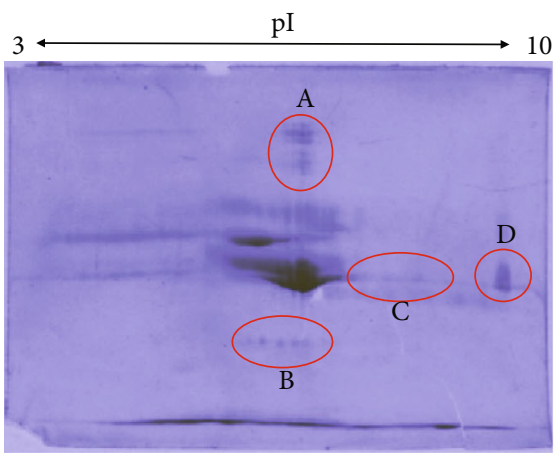

Control

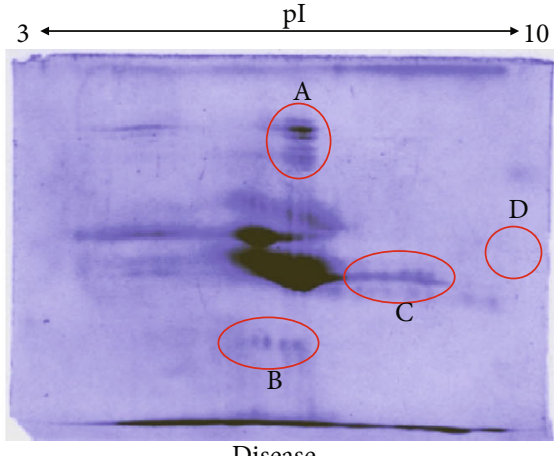

Disease

FIGURE 3: 2D gel electrophoretic profile of saliva: differential protein expression of pooled saliva from control and dental caries patients. Red circles labelled A, B, C, and D show proteins differentially expressed in both groups.

$[48,49]$. Contrary to our study, others observed an inverse relationship between salivary sIgAs and dental caries [50]. At the same time, a few studies did not find any association between the two $[51,52]$. These contradictory observations may be attributed to different saliva sampling methods, exposure to different environmental factors, and inclusion criteria used for subject selection. Also, salivary IgA levels are affected by age, pregnancy, presence of any other systemic disease, salivary flow rate, use of medications, hormonal changes, and physical activity. Therefore, studies using standardized sample collection and large sample size must be carried out to clearly establish sIgA role in dental caries [53]. 


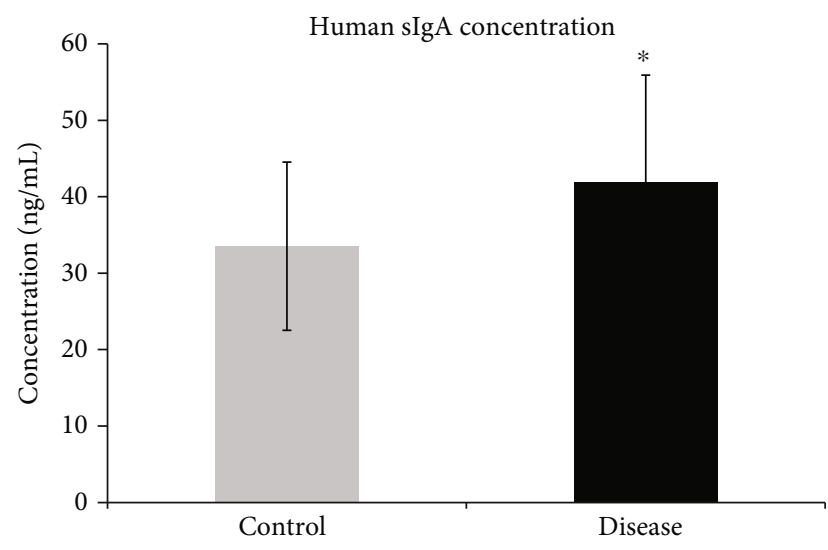

FIGURE 4: sIgA detection by ELISA: concentration of human $\operatorname{sIgA}$ is specified as mean \pm SD. Analysis of the data was performed by Student's $t$-test (unpaired). A result with $p$ values $<0.05$ was considered statistically significant. Asterisk $(*)$ indicates statistically significant difference.

TABLE 1: Comparison of salivary secretory immunoglobulin A (sIgA) in control and dental caries patients in nanograms per milliliter.

\begin{tabular}{lccc}
\hline Groups & Lowest value & Highest value & $($ mean \pm SD) \\
\hline Control & 13.8 & 49.0 & $33.53 \pm 11.59$ \\
Disease & 7.47 & 67.7 & $41.89 \pm 14.82$ \\
\hline
\end{tabular}

The comparison of 2D gels of both groups showed four regions (encircled in red) in Figure 3 where differential protein expression in caries was observed. Among those, circles $\mathrm{A}, \mathrm{B}$, and $\mathrm{C}$ indicate the increased expression in disease condition (Figure 3, circles A, B, and C) whereas circle D showed downregulation (Figure 3, circle D). These highly expressed protein in the caries group could be attributed to many of the immune factors and other protein constituents of saliva. These include salivary IgAs (expected Figure 3, circle A), cystatins (expected Figure 3, circle B), and prolinerich proteins (expected Figure 3, circle $\mathrm{C}$ ) as reported in salivary proteome analysis on $2 \mathrm{D}$ gels $[47,54,55]$. A dense band observed at the center for gel is expected to be salivary albumin, amylases, and immunoglobulins that interact with each other and other proteins to form an interactome. The other factor for such an observation could be the pooling of samples that may have enhanced the interactome effect of the sample. Moreover, it has been reported that almost 66 different proteins were found to interact with amylases only. This suggests its additional role in transport and protection of its partner proteins [56]. Cystatins and proline-rich proteins along with statherin inhibit bacterial and viral pathogens to maintain salivary calcium levels, enhance remineralization, and thereby serve a protective role in maintaining teeth integrity [57]. This could also be an element to increased expression of protein spots observed in dental caries patients indicating host immune response to combat the disorder. However, mass spectrometric analysis of salivary $2 \mathrm{D}$ gels is further required to accurately identify the presence and upregulation of these proteins. The need to look into the posttranslational modifications such as the phosphoproteome and glycoproteome of salivary proteins would be of great interest and a side that is lacking. Specifically, the glycoproteome studies would provide excessive support in this regard in salivary diagnostics [58].

\section{Conclusions}

Dental caries is the most prevalent oral disease that involves demineralization and breakdown of dental hard tissue in the presence of acidic environment produced by oral microbes. The protein profiling of control and diseased saliva samples on SDS-PAGE and 2D-electrophoresis showed certain expressional differences. However, proteolytic activity and mean sIgA levels were significantly higher in caries active patients. The present study is among the initial studies for identification of salivary proteins in dental caries patients in the local community. Our analysis has demonstrated a good potential to identify protein differences due to dental caries.

\section{Abbreviations}

ELISA: $\quad$ Enzyme-linked immunosorbent assay

2D-electrophoresis: Two-dimensional electrophoresis

SDS-PAGE: $\quad$ Sodium dodecyl sulfate-polyacrylamide

gel electrophoresis

PRP: $\quad$ Proline-rich proteins

sIgAL: $\quad$ Secretory immunoglobulin A

MMP: $\quad$ Matrix metalloproteinase

BSA: $\quad$ Bovine serum albumin

BCA: $\quad$ Bicinchoninic acid

IPG Strips: Immobilized $\mathrm{pH}$ gradient strips

IEF: Isoelectric focusing.

\section{Data Availability}

The data used to support the findings of this study are included within the article.

\section{Conflicts of Interest}

The authors declare that they have no conflict of interest.

\section{Authors' Contributions}

Zaid Majeed Khan and Syed Faraz Moin were responsible for the conceptualization. Muhammad Sohail Zafar was responsible for data curation. Zaid Majeed Khan, Humera Waheed, Muhammad Sohail Zafar, and Syed Faraz Moin were responsible for the formal analysis. Zaid Majeed Khan, Humera Waheed, and Syed Faraz Moin were responsible for the investigation. Zaid Majeed Khan, Humera Waheed, and Zohaib Khurshid were responsible for the methodology. M. Khursheed Alam, Zohaib Khurshid, Muhammad Sohail Zafar, and Syed Faraz Moin were responsible for the project administration. Muhammad Sohail Zafar was responsible for the software. Syed Faraz Moin, Zohaib Khurshid, and Muhammad Sohail Zafar were responsible for the supervision, Humera Waheed, Zohaib Khurshid, and Syed Faraz 
Moin were responsible for writing-original draft. M. Khursheed Alam, Zohaib Khurshid, and Syed Faraz Moin were responsible for writing, review, and editing.

\section{Acknowledgments}

The authors acknowledge Ms. Tabinda Salman for the support in analysis of ELISA.

\section{References}

[1] GBD 2017 Oral Disorders Collaborators, E. Bernabe, W. Marcenes et al., "Global, regional, and national levels and trends in burden of oral conditions from 1990 to 2017: a systematic analysis for the Global Burden of Disease 2017 study," Journal of dental research, vol. 99, no. 4, pp. 362-373, 2020.

[2] N. Pitts, D. Zero, P. Marsh et al., "Dental caries," Nature Reviews. Disease Primers, vol. 3, no. 1, p. 17030, 2017.

[3] R. Holt, G. Roberts, and C. Scully, "Dental damage, sequelae, and prevention," BMJ, vol. 320, no. 7251, pp. 1717-1719, 2000.

[4] W. J. Loesche, Microbiology of dental decay and periodontal disease, Medical Microbiology, 4th edition, 1996.

[5] R. Touger-Decker and C. Van Loveren, "Sugars and dental caries," The American Journal of Clinical Nutrition, vol. 78, no. 4, pp. 881S-892S, 2003.

[6] P. B. Hunter, "Risk factors in dental caries," International Dental Journal, vol. 38, no. 4, pp. 211-217, 1988.

[7] A. Punj, "Secretions of human salivary gland," in Salivary Glands-New Approaches in Diagnostics and Treatment, IntechOpen, 2018.

[8] Z. Khurshid, J. A. Haq, R. Khan, M. Altaf, and S. Najeeb, "Human saliva and its role in oral \& systemic health," JPDA, vol. 25, no. 4, p. 171, 2016.

[9] C. Dawes, A. L. Pedersen, A. Villa et al., "The functions of human saliva: a review sponsored by the world workshop on oral medicine VI," Archives of Oral Biology, vol. 60, no. 6, pp. 863-874, 2015.

[10] H. Jasim, P. Olausson, B. Hedenberg-Magnusson, M. Ernberg, and B. Ghafouri, "The proteomic profile of whole and glandular saliva in healthy pain-free subjects," Scientific Reports, vol. 6, no. 1, pp. 1-10, 2016.

[11] J. Tenovuo, M. Lumikari, and T. Soukka, "Salivary lysozyme, lactoferrin and peroxidases: antibacterial effects on cariogenic bacteria and clinical applications in preventive dentistry," Proc Finn Dent Soc, vol. 87, no. 2, pp. 197-208, 1991.

[12] A. M. L. Pedersen and D. Belstrøm, "The role of natural salivary defences in maintaining a healthy oral microbiota," Journal of Dentistry, vol. 80, pp. S3-S12, 2019.

[13] Z. Khurshid, M. Naseem, Z. Sheikh, S. Najeeb, S. Shahab, and M. S. Zafar, "Oral antimicrobial peptides: types and role in the oral cavity," Saudi Pharmaceutical Journal, vol. 24, no. 5, pp. 515-524, 2016.

[14] K. S. Ambatipudi, F. K. Hagen, C. M. Delahunty et al., "Human common salivary protein 1 (CSP-1) promotes binding of Streptococcus mutans to experimental salivary pellicle and glucans formed on hydroxyapatite surface," Journal of Proteome Research, vol. 9, no. 12, pp. 6605-6614, 2010.

[15] J. A. Loo, W. Yan, P. Ramachandran, and D. T. Wong, "Comparative human salivary and plasma proteomes," Journal of Dental Research, vol. 89, no. 10, pp. 1016-1023, 2010.
[16] R. Haeckel and P. Hänecke, "Application of saliva for drug monitoring. An in-vivo model for transmembrane transport," European journal of clinical chemistry and clinical biochemistry: journal of the Forum of European Clinical Chemistry Societies, vol. 34, no. 3, pp. 171-191, 1996.

[17] Z. Khurshid, M. S. Zafar, S. Najeeb, and S. Zohaib, "Human saliva: a future diagnostic tool," EC Dental Science, vol. 3, no. 6, pp. 635-636, 2016.

[18] N. Malathi, S. Mythili, and H. R. Vasanthi, "Salivary diagnostics: a brief review," International Scholarly Research Notices, vol. 2014, 8 pages, 2014.

[19] J. Cunha-Cruz, J. Scott, M. Rothen et al., "Salivary characteristics and dental caries: evidence from general dental practices," The Journal of the American Dental Association, vol. 144, no. 5, pp. e31-e40, 2013.

[20] A. Jafarzadeh, M. Sadeghi, G. A. Karam, and R. Vazirinejad, "Salivary IgA and IgE levels in healthy subjects: relation to age and gender," Brazilian Oral Research, vol. 24, no. 1, pp. 21-27, 2010.

[21] H. Marcotte and M. C. Lavoie, "Oral microbial ecology and the role of salivary immunoglobulin A," Microbiology and molecular biology reviews, vol. 62, no. 1, pp. 71-109, 1998.

[22] E. Ranadheer, U. A. Nayak, N. V. Reddy, and V. A. P. Rao, "The relationship between salivary IgA levels and dental caries in children," Journal of Indian Society of Pedodontics and Preventive Dentistry, vol. 29, no. 2, pp. 106-112, 2011.

[23] P. R. Geetha Priya, S. Asokan, K. Karthick, N. V. Reddy, and V. A. P. Rao, "Effect of dental treatments on salivary immunoglobulin A of children with and without dental caries: a comparative study," Indian Journal of Dental Research, vol. 24, no. 3, p. 394, 2013.

[24] P. Soesilawati, H. Notopuro, Y. Yuliati, M. D. Ariani, and M. A. B. Firdauzy, "The role of salivary sIgA as protection for dental caries activity in Indonesian children," Clinical, Cosmetic and Investigational Dentistry, vol. 11, pp. 291-295, 2019.

[25] A. Jain and R. Bahuguna, "Role of matrix metalloproteinases in dental caries, pulp and periapical inflammation: An Overview," Journal of Oral Biology and Craniofacial Research, vol. 5, no. 3, pp. 212-218, 2015.

[26] A. Mazzoni, L. Tjäderhane, V. Checchi et al., "Role of dentin MMPs in caries progression and bond stability," Journal of Dental Research, vol. 94, no. 2, pp. 241-251, 2015.

[27] Y. Shimada, S. Ichinose, A. Sadr, M. F. Burrow, and J. Tagami, "Localization of matrix metalloproteinases (MMPs-2, 8, 9 and 20) in normal and carious dentine," Australian dental journal, vol. 54, no. 4, pp. 347-354, 2009.

[28] P. K. Smith, R. I. Krohn, G. T. Hermanson et al., "Measurement of protein using bicinchoninic acid," Analytical Biochemistry, vol. 150, no. 1, pp. 76-85, 1985.

[29] K. J. Wiechelman, R. D. Braun, and J. D. Fitzpatrick, "Investigation of the bicinchoninic acid protein assay: identification of the groups responsible for color formation," Analytical Biochemistry, vol. 175, no. 1, pp. 231-237, 1988.

[30] U. K. Laemmli, "Cleavage of structural proteins during the assembly of the head of bacteriophage T4," Nature, vol. 227, no. 5259, pp. 680-685, 1970.

[31] Z. Khurshid, S. F. Moin, R. S. Khan, M. A. S. Agwan, A. H. Alwadaani, and M. S. Zafar, "Human salivary protein extraction from RNAPro· $S A L^{\mathrm{TM}}$, Pure. $\mathrm{SAL}^{\mathrm{TM}}$, and passive drooling method," European journal of dentistry, vol. 11, no. 3, pp. 385-389, 2017. 
[32] J. A. Banderas-Tarabay, I. G. Zacarias-D’Oleire, R. GarduñoEstrada, E. Aceves-Luna, and M. González-Begné, "Electrophoretic analysis of whole saliva and prevalence of dental caries. A study in Mexican dental students," Archives of medical research, vol. 33, no. 5, pp. 499-505, 2002.

[33] M. Ayad, B. C. Van Wuyckhuyse, K. Minaguchi et al., "The association of basic proline-rich peptides from human parotid gland secretions with caries experience," Journal of Dental Research, vol. 79, no. 4, pp. 976-982, 2000.

[34] R. Mengi, R. Kaul, V. Kaul, and H. Mengi, "Electrophoretic analysis of whole saliva and prevalence of dental caries . A study in Indian population," International Journal of Scienctific Research, vol. 10, no. 6, pp. 163-165, 2017.

[35] S. Schwartz, W. Zhu, and L. Sreebny, "Sodium dodecyl sulphate-polyacrylamide gel electrophoresis of human whole saliva," Archives of Oral Biology, vol. 40, no. 10, pp. 949-958, 1995.

[36] R. S. Khan, Z. Khurshid, and F. Yahya Ibrahim Asiri, “Advancing point-of-care $(\mathrm{PoC})$ testing using human saliva as liquid biopsy," Diagnostics, vol. 7, no. 3, p. 39, 2017.

[37] M. Lenander-Lumikari, J. Tenovuo, C. G. Emilson, and P. Vilja, "Viability of Streptococcus mutans and Streptococcus sobrinus in whole saliva with varying concentrations of indigenous antimicrobial agents," Caries research, vol. 26, no. 5, pp. 371-378, 1992.

[38] M. Maciejczyk, A. Pietrzykowska, A. Zalewska, M. Knaś, and I. Daniszewska, "The significance of matrix metalloproteinases in oral diseases," Adv Clinical and Experimental Medicine, vol. 25, no. 2, pp. 383-390, 2016.

[39] F. D. Nascimento, C. L. Minciotti, S. Geraldeli et al., "Cysteine cathepsins in human carious dentin," Journal of Dental Research, vol. 90, no. 4, pp. 506-511, 2011.

[40] C. Chaussain-Miller, F. Fioretti, M. Goldberg, and S. Menashi, "The role of matrix metalloproteinases (MMPs) in human caries," Journal of Dental Research, vol. 85, no. 1, pp. 22-32, 2006.

[41] C. Loreto, C. Galanti, G. Musumeci, M. C. Rusu, and R. Leonardi, "Immunohistochemical analysis of matrix metalloproteinase-13 in human caries dentin," European Journal of Histochemistry, vol. 58, no. 1, pp. 47-51, 2014.

[42] K. A. Benarji, K. R. Lakshmi, H. Nelakurthi, P. Haritha, and R. Amrutha, "Cathepsins in oral diseases," Journal of Dr. NTR University of Health Sciences, vol. 8, no. 3, pp. 153-158, 2019.

[43] P. Bencsik, M. Bartekova, A. Görbe et al., "MMP activity detection in zymograms," in Zymography, pp. 53-70, Humana Press, New York, NY, 2017.

[44] J. Wilkesman and L. Kurz, "Protease analysis by zymography: a review on techniques and patents," Recent Patents on Biotechnology, vol. 3, no. 3, pp. 175-184, 2009.

[45] B. Corthésy, "Multi-faceted functions of secretory IgA at mucosal surfaces," Frontiers in Immunology, vol. 4, pp. 1-11, 2013.

[46] P. Brandtzaeg, "Secretory IgA: designed for anti-microbial defense," Frontiers in Immunology, vol. 4, pp. 1-17, 2013.

[47] B. Ghafouri, C. Tagesson, and M. Lindahl, "Mapping of proteins in human saliva using two-dimensional gel electrophoresis and peptide mass fingerprinting," Proteomics, vol. 3, no. 6, pp. 1003-1015, 2003.

[48] D. G. de Farias and A. C. B. Bezerra, "Salivary antibodies, amylase and protein from children with early childhood caries," Clinical Oral Investigations, vol. 7, no. 3, pp. 154-157, 2003.
[49] S. Thaweboon, B. Thaweboon, S. Nakornchai, and S. Jitmaitree, "Salivary secretory IgA, pH, flow rates, mutans Streptococci and Candida in children with rampant caries," Southeast Asian J. Trop Med. Public Health, vol. 39, no. 5, pp. 893-899, 2008.

[50] D. Doifode and S. Damle, "Comparison of salivary IgA levels in caries free and caries active children," International Journal of Clinical Dental Science, vol. 2, no. 1, pp. 10-14, 2011.

[51] C. Y. Koga-Ito, C. A. D. P. Martins, I. Balducci, and A. O. C. Jorge, "Correlation among mutans streptococci counts, dental caries, and IgA to Streptococcus mutans in saliva," Brazilian Oral Research, vol. 18, no. 4, pp. 350-355, 2004.

[52] S. Shifa, M. Muthu, D. Amarlal, and V. R. Prabhu, "Quantitative assessment of IgA levels in the unstimulated whole saliva of caries-free and caries-active children," Journal of Indian Society of Pedodontics and Preventive Dentistry, vol. 26, no. 4, pp. 158-161, 2008.

[53] T. K. da Silva Fidalgo, L. B. Freitas-Fernandes, M. Ammari, C. T. Mattos, I. P. R. de Souza, and L. C. Maia, "The relationship between unspecific s-IgA and dental caries: a systematic review and meta-analysis," Journal of Dentistry, vol. 42, no. 11, pp. 1372-1381, 2014.

[54] S. Talungchit, W. Buajeeb, C. Lerdtripop et al., "Putative salivary protein biomarkers for the diagnosis of oral lichen planus: a case-control study," BMC Oral Health, vol. 18, no. 1, p. 42, 2018.

[55] F. Chevalier, C. Hirtz, S. Chay et al., "Proteomic studies of saliva: a proposal for a standardized handling of clinical samples," Clinical Proteomics, vol. 3, no. 1, pp. 13-21, 2007.

[56] K. T. B. Crosara, D. Zuanazzi, E. B. Moffa, Y. Xiao, M. A. d. A. M. Machado, and W. L. Siqueira, "Revealing the amylase interactome in whole saliva using proteomic approaches," BioMed Research International, vol. 2018, 15 pages, 2018.

[57] A. S. Hemadi, R. Huang, Y. Zhou, and J. Zou, "Salivary proteins and microbiota as biomarkers for early childhood caries risk assessment," International Journal of Oral Science, vol. 9, no. 11, pp. 1-8, 2017.

[58] S. Ruhl, "The scientific exploration of saliva in the postproteomic era: from database back to basic function," Expert Review of Proteomics, vol. 9, no. 1, pp. 85-96, 2012. 